\title{
Postnatal quality of life - a content analysis of qualitative results to the Mother-Generated Index
}

Susanne Grylka-Baeschlin, Thorsten Meyer, Luise Lengler, Edwin van Teijlingen, Jessica Pehlke-Milde, Mechthild M. Gross

Susanne Grylka-Baeschlin, MSc, PhD, Midwifery Research and Education Unit, Hannover Medical School, Carl-Neuberg-Str. 1, D-30625 Hannover, Germany and Institute of Midwifery, Zurich University of Applied Sciences ZHAW,

Technikumstrasse 81, CH-8401 Winterthur, Switzerland, Susanne.Grylka@zhaw.ch

Thorsten Meyer, Prof. Dr., University of Bielefeld, School of Public Health, Universitätsstr. 25, 33615 Bielefeld, thorsten.meyer@uni-bielefeld.de, Tel. 0049521 10667606

Luise Lengler, BSc (hons), MSc, Midwifery Education Unit, University of Freiburg, Fehrenbachallee 8, 79106 Freiburg, Germany, luise.lengler@t-online.de

Edwin van Teijlingen, PhD, Prof., Centre for Midwifery, Maternal \& Perinatal Health, Bournemouth University, Bournemouth House, 19, Christchurch Road, Bournemouth BU1 3LH, United Kingdom, evteijlingen@bournemouth.ac.uk

Jessica Pehlke-Milde, BSc, MSc, Prof. Dr., Institute of Midwifery, Zurich Universities of Applied Sciences ZHAW, Technikumstrasse 81, CH-8401 Winterthur, Switzerland, Jessica.Pehlke-Milde@zhaw.ch

Mechthild M. Gross, BSc, MSc, Prof. Dr., Midwifery Research and Education Unit, Hannover Medical School, Carl-Neuberg-Str. 1, D-30625 Hannover Germany, Gross.Mechthild@mh-hannover.de

Corresponding author: Susanne Grylka-Baeschlin, MSc, PhD, Midwifery Research and Education Unit, Hannover Medical School, Carl-Neuberg-Str. 1, D-30625 Hannover, Germany and Institute of Midwifery, Zurich University of Applied Sciences ZHAW, Technikumstrasse 81, CH-8401 Winterthur, Switzerland, Susanne.Grylka@zhaw.ch, Tel. +4158934 4377 


\section{Abstract}

Background: The Mother-Generated Index (MGI) assesses postnatal quality of life (QoL) without providing a predefined checklist, thus offering mothers the opportunity to identify areas of life affected by having a baby.

Aim: To identify: a) details and particularities of areas of life affected after childbirth and thus specific domains defining postnatal QoL; b) changes in the importance of domains specifying QoL within the first weeks postpartum; and c) the potential role of cultural differences with regard to the nature of QoL definitions.

Methods: Prospective, cross-cultural, longitudinal survey. We applied a qualitative content analysis to MGI data collected in Switzerland and Germany using combined deductively and inductively category building.

Results: Women participated at three days $(n=124)$ and six and a half weeks $(n=82)$ postpartum. Eleven domains were identified, each with several subdomains: 'physical wellbeing' (e.g. fatigue), 'psychological well-being' (e.g. happiness, emotional confusion), 'general well-being', 'motherhood' (e.g. bonding with the baby), 'family and partnership' (e.g. time for partner and children), 'social life' (e.g. friends, being isolated), 'everyday life' (e.g. organisation daily routine), 'leisure' (e.g. less time), 'work life' (e.g. worries about job), 'financial issues' (e.g. less money), and further aspects. The most frequently indicated domains were 'motherhood' and 'family and partnership'. Differences between the stages of assessment and countries were identified.

Discussion: Mothers faced challenges in defining their new role but welcomed the slowdown in the rhythm of life and experienced overwhelming maternal feelings.

Conclusion: Our findings suggest that postnatal QoL is a concept that changes over time and differs between countries.

Keywords: MGI; QoL; well-being; postpartum; change over time; cross-cultural 


\section{Statement of significance}

Problem
Postnatal quality of life (QoL) lacks a clear definition and little is known about changes of
Woctors during the first weeks after birth and its cross-cultural differences.
Previous studies identified a variety of areas affected postnatally without a clear
categorisation. Numerical results of QoL measures showed changes over time and
differences between countries.
What this paper adds
A well-defined system of domains and subdomains defining postnatal QoL was provided.
Important changes in the QoL content between weeks one and seven postpartum and
differences between German and Swiss mothers were found. Asking women to complete
the MGI can assist midwives and other maternity care providers in identifying the care
needs of individual women.




\section{Background}

Postnatal quality of life (QoL) is a salutogenically-focused outcome of maternity care. It is also a concept which needs detailed investigation to help improve the support of women after childbirth and, hence their well-being. QoL is a multidimensional construct which depends on the life situation and includes both physical and psychological health as well as social and economic concerns, but lacks a uniform and clear definition. ${ }^{1-5}$

A shift toward salutogenic outcomes in maternity care has been observed. ${ }^{5,6}$ Health care outcomes usually focus on mortality and morbidity, but the consideration of QoL as an additional outcome that widens the traditional pathology-focused ones has been recommended. ${ }^{5-7}$ A systematic review identified 16 salutogenically-focused outcome categories including maternal satisfaction and breastfeeding as the most common ones as well as wellbeing and QoL. ${ }^{6}$ However, only a few studies considered QoL as an outcome of childbirth and maternity care ${ }^{8-11}$ although knowledge about factors which are associated with QoL and wellbeing of women after childbirth are essential for optimising maternity care.

Emmanuel and Sun ${ }^{12}$ observed changes in health-related QoL during the perinatal period with improvement after birth compared to pregnancy and further amelioration during the first weeks after birth. Symon and Dobb ${ }^{13}$ also found higher QoL six to eight weeks after birth compared to pregnancy. The improvement after birth was confirmed by Bahrami et al. ${ }^{14}$ who found more favourable scores at 12 to 14 weeks compared to six to eight weeks postpartum. However, XXX et al. ${ }^{11}$ observed higher postnatal QoL at a median of three days after birth compared to six and a half weeks postpartum. This might be due to the closeness of the assessment to the birth and the subsequent overwhelming feelings in the first days after birth. Life satisfaction was also found to increase during the postnatal period. ${ }^{15}$ Postpartum support and home visits seem to decrease postnatal stress and increase postnatal quality of life as well. ${ }^{9}$ Supporting women after birth in order to increase postnatal quality of life could 
be facilitated by having more knowledge about the most important factors associated with postnatal QoL.

Most studies investigating quality of life in maternity care use instruments, such as the SF36, which were not developed for this specific health care and life situation. ${ }^{5,16}$ Two published instruments were developed especially for the assessment of postpartum QoL: The MotherGenerated Index (MGI) developed by Symon et al. ${ }^{17}$ and the Maternal Postpartum Quality of Life (MAPPQOL) tool. ${ }^{18}$ The MAPPQOL includes five defined domains which are called psychological/baby, socioeconomic, relational with partner, relational with family and friends as well as health related aspects. ${ }^{18}$ The MGI in contrast, does not include a predefined list of topics. ${ }^{19}$ In a first step, mothers are asked to identify for themselves areas of life which were affected by motherhood (Figure 1). There is also an additional column where women indicate if this area of life is positive, negative or both/neither. In a second step, women rate on visual analog scales how they felt about the formerly mentioned aspect during the last month or since giving birth. In a third step, the importance of the identified areas of life is assessed. ${ }^{19}$ In addition to two scores which allow numerical identification of high and low quality of life, women provide information about domains of their life in which they experience important changes after giving birth. Several studies have reported on qualitative analyses of these areas of life. ${ }^{19-22}$ These qualitative studies revealed a variety of aspects such as for example, physical complaints, emotional-mental health, financial worries, working life and social life, tiredness, less personal time, less time with partner/rest of family and worse relationship with partner or another family member. In the main, a logical structure of these aspects was lacking and no previous study investigated changes during the first few weeks after birth and differences between countries.

There is a lack of knowledge about possible factors defining postnatal quality of life as well as changes of QoL during the postnatal period, even though this knowledge is important to understand the needs of postpartum women and provide optimised maternity care. The aims of this paper were therefore to investigate: a) details and particularities of the areas of life 
affected after childbirth and thus to identify specific domains and subdomains defining postnatal QoL; b) changes in the importance of domains specifying QoL within the first weeks postpartum; and c) the potential role of cultural differences with regard to the content of QoL definitions.

\section{Methods}

\section{Study design, setting and participants}

This paper presents the qualitative content analysis of the areas of life which were mentioned by German and Swiss mothers as being affected by having a baby by completing the MGI in a prospective, cross-cultural, longitudinal survey. Translation and validation of the $\mathrm{MGI}^{23}$ and its use for cross-cultural comparison ${ }^{11}$ have been published elsewhere.

The survey was carried out in late 2012 in two small rural hospitals, one in the south of Germany and the other in the north of Switzerland. The hospitals both had between 500 and 600 births per year and did not offer neonatal intensive care. The sites were situated in the same geographical area within five kilometers of the border. Geographical differences and structural differences at the hospital level were small to enable cross-cultural comparison of detailed results of the MGI and their associations with maternity care. ${ }^{11}$ However, perinatal care differed partially during the study period. The German hospital had higher rates of epidural anesthesia than the Swiss hospital ( 50.8 vs $20.0 \%, p<0.01)$ and the Swiss hospital had higher caesarean section rates compared to the German one (44.2 vs $25.0 \%, p=0.02) .{ }^{11}$

Women were eligible for study participation if they gave birth in one of the study locations during the determined study period, had fluent German knowledge and if their baby was not in need of intensive neonatal care. The first questionnaire was distributed to 226 women during their hospital stay on the postpartum wards, and 129 new mothers participated (response rate $57.1 \%$ ) at a median of three days after birth (interquartile range 2-3 days). A total of 124 of these 129 women completed the MGI form and their comments could be used for the content analysis. Of 98 women agreeing to receive a second questionnaire, which 
was sent five and a half to six weeks after birth by post, a total of 83 participated (response rate $84.7 \%$ ) in a median of six and a half weeks postpartum (interquartile range 6.0-7.5 weeks). All but one woman ( $n=82$ ) participating in the follow up completed the MGI form. One woman who did not complete the first stage of assessment did so at the second stage.

The study received approval from the Ethics Committee of Hannover Medical School (15562012).

\section{Study instrument}

The questionnaires which were distributed during the first days after birth and six weeks postpartum were similar. ${ }^{11,23}$ Both questionnaires contained the translated MGI and additional questions regarding socio-demographic and perinatal information. For this qualitative content analysis, the first step of completing the MGI, where women wrote down the areas of life which were affected by the motherhood, was of interest (Figure 1). Women had between one and eight rows at their disposal to report the domains of their life in which they experienced important changes after giving birth. The text written in these rows constitutes the study material for the qualitative analysis.

\section{Content analysis}

The texts were transcribed by writing the exact wording of each row into one cell of an Excel sheet. On some rows, only key words were written but on others, long sentences containing different affected areas of life were entered. As a result of many written keywords, the material left a partially paraphrased impression. A combined deductively and inductively category building was applied. ${ }^{24,25}$ Studies which used the MGI and analysed the areas of life identified by women and general literature on QoL were reviewed, analysing domains which have a potential impact on health-related QoL. ${ }^{1,2,19,21,22}$ Theory based studies ${ }^{1-3}$ were used to identify the main categories for the draft of the coding scheme such as physical and mental health, well-being, social relationships, financial situation and meaning of life. The examples of areas of life provided on the MGI form ${ }^{13}$ further amended the draft of the coding scheme 
(Figure 1). Additionally, Symon et al. ${ }^{19,20}$, Nagpal et al. ${ }^{21}$ and Khabiri et al. ${ }^{22}$ all used the MGI and identified a variety of areas of life affected by the birth without categorising them in a clear scheme, but providing an additional base for the system of categories. The first draft for the coding scheme included three levels of categories: main categories, subcategories and an assessment of the women's particular areas of QOL as either "positive", "both/either" or "negative" (Figure 1). Thereafter, 20 randomly selected questionnaires, five from each site and from both stages of assessment, were coded by the first author (SG) and a first coding scheme was developed.

Next two coders coded 20 further randomly selected MGI forms according to the preliminary coding scheme. One coder with a master degree in midwifery (LL) lived in the south of Germany and the other one, a student in health sciences (MG), lived in the north of Switzerland. This enabled the linguistic and cultural differences between the German speaking countries to be respected and different disciplinary perspectives to be included. The coders were asked to choose a main and a sub-category for each aspect recorded by women on the MGI and to assess the third level (positive, negative, neither or missing). Further instructions were that an aspect could contain and be coded as two or more areas of life and that unclear items should be coded as "other" to be developed into further categories if appropriate. This procedure was then repeated, and the coding scheme was further improved before all questionnaires were coded by both coders (LL and MG) and a consensus on disparate codings was reached in discussion with the main investigator (SG). Full agreement on coding of all questionnaires was $72 \%$ (Table 1). In a next step, LL and SG assessed similarities of the areas of life which were coded as "other" in order to find further specific aspects defining postnatal Qol. During this step, main and subcategories were added to the coding scheme and the definitive categories and subcategories were generated (Table 2). Frequencies of aspects in each main and subdomain at both stages of assessment were recorded. To establish relative importance, frequencies, variability of the aspects and the specificity for the context, meaning the life 
situation during the postpartum period were considered, as well as linguistic differences between German and Swiss mothers. Domains, subdomains and quotes were then translated into English and were checked by two bilingual speakers, one native German speaker and one native English speaker.

\section{Results}

A total of 124 women completed the MGI, at a median of three days after birth, 74 at the German and 50 at the Swiss site. In the follow-up, at a median of six and a half weeks postpartum, 82 women completed the MGI, 44 at the German and 38 at the Swiss site.

Eleven main domains defining postnatal QoL were identified: 'Physical well-being', 'Mental well-being', 'General well-being', 'Motherhood', 'Family and partnership', 'Social life', 'Everyday life', 'Leisure', 'Work life', 'Financial issues' and 'Further aspects' (Table 2). Each domain included various subdomains. The proportion of women who indicated if the aspects were positive, negative or both/neither was $92 \%$ after three days and $88 \%$ after six and a half weeks.

\section{Physical well-being}

'Physical well-being' was mentioned frequently at both stages of assessment (Table 2).

During the first week after birth, positive and negative comments about the physical conditions were balanced. Examples of negative aspects included: "Physical (perineal scar)" or "Physical (caesarean section)". After six and a half weeks, the responses were more positive, such as "I feel completely physically balanced". Pain due to childbirth was recognised during the first days, e.g. "Physical pain when sitting", but was not mentioned during the seventh week postpartum. Being tired, in contrast, was indicated more frequently after six and a half weeks compared to three days postpartum. One women commented during the first week after birth "Tired but good", but during the seventh week postpartum, lack of sleep mostly caused tiredness: "Too little sleep, two small children". Body awareness could be positive e.g. "The body awareness is positive despite/because of the change" or 
negative, e.g. sport was mostly negatively affected by having the baby. Further negative aspects were: "Not being physically intact anymore (caesarean section)"; "Changed body shape, body tissue in contrast to the ideal of beauty" or "Weight gain". There were also further positive physical factors such as "Back to the old body".

\section{Mental well-being}

'Psychological well-being' included several subdomains (Table 2). At both stages of assessment, comments about psychological well-being were mostly positive or ambivalent and the frequency of aspects mentioned was similar. Positive emotional aspects were: "I feel emotional" or "Emotionality increases". A negative comment stated "Emotionally still stressed" and an ambivalent comment was "Emotional instability (sometimes crying without any reason)". Happiness as a positive feeling was described as "Indescribable feelings of happiness" or "Very happy". Self-esteem was also a positive aspect, but no further explanations were provided by the women. A variety of further positive comments were identified, such as "Serenity increases" and negative ones, such as "Inner chaos" and "Fear of doing something wrong".

\section{General well-being}

One of the examples of potential areas of life affected by having a baby which were included on the MGI form stated "How they feel about themselves" (Figure1) without any indication if this feeling was physical or emotional. This comment was used by many participants without further explanations at both stages of assessment, hence the main category 'General wellbeing' incorporated the subcategory 'How I feel' (Table 2). This category was mostly positive, rarely negative and sometimes both/neither. An example of a further positive aspect of general well-being was "I feel strongly changed".

\section{Motherhood}

Aspects coded in the main domain 'Motherhood' were the second most common responses at both time points (Table 2). Comments in this domain varied. 'Feelings for the baby' were 
almost always positive such as "Unconditional love for the baby" and only one woman mentioned that the feeling for the baby was ambivalent. 'Mother-child relationship' contained comments such as "Very strong bonding with the baby" or "Relationship with the baby". Some women indicted worries about the baby: "Is my baby well" or "Fear about the baby". Breastfeeding during the first week was positive for some women but negative for others, and was recognised to be mostly positive after six and a half weeks. One ambivalent comment was "Guilty conscience that I'm not able to manage the breastfeeding period completely, respectively to feed the baby well". In the first days some women also mentioned their experiences of pregnancy and childbirth, however after six and a half weeks, this was not noted anymore. Positive comments were "Course of pregnancy", "Birth experience (emotional)" and also "Proud to have had a spontaneous breach birth" and negative ones "Uncertainty about the birth outcome" and "Feeling to be helpless during birth (low selfcontrol and self-efficacy)". Maternity care in the hospital was only indicated during the first days after birth. A positive comment was "Midwifery care in the hospital" but another woman indicated "Postpartum care in the hospital" as being negative. There was a variety of further aspects which were mostly positive: "Feelings of having created something big and wonderful", "To care again for someone small, hold a baby in my arms" or after six and a half weeks "The baby is already sleeping through". An ambivalent woman mentioned "Will I be able to manage it with my baby?".

\section{Family and partnership}

Comments about family and partnership were indicated most often and the variety of the aspects in the seven subdomains was huge (Table 2). A few days after birth, the 'Relationship with the partner' was mostly positive. During the seventh week postpartum however, this relationship was more often ambivalent or negative compared to three days after birth. Positive comments about the partnership included: "Feelings for the partner", "Relationship with the partner, more cohesion and mutual trust" or "Care for the partnership and care together for the baby". However, negative aspects such as "Relationship with the 
partner strained" were found at the six and a half week assessment. Sexuality was mentioned rarely at both time points, it was never assessed positively after three days, but it was at six and a half weeks. Women did not provide further information and wrote just "Sexuality" or "Love life with partner". The relationship with the other children was mostly positive at both time points, with comments such as "Feelings for my two older children" but comments did not provide further information. The relationship with other family members was also mostly positive with comments such as "Better relationship with parents" or "Relationship with own mother". A negative comment was "The relationship with the family (my family)". Time for the family was mostly positive three days after birth and more often negative or ambivalent after six and a half weeks. A positive aspect was "Time for older sister", a negative one "Time for my first child decreased" and an ambivalent one "Everyday life with children, do I have enough time for both". At both time points a variety of further aspects was found which were mostly positive: "Our baby, part of us", "A healthy family" or "Family cohesion". An ambivalent quote, which was "Personal requirements" and negative ones were "Me as a person with own wishes", "Afraid that my first child feels neglected".

\section{Social life}

Social life was mentioned more often after six and a half weeks than after three days, and four subdomains were identified (Table 2). 'Social contacts' were mostly indicated to be positive. The content of the comments was not very rich, mainly consisting of general phrasing such as "Social contacts" and "Social environment". An aspect which was indicated to be ambivalent was "Changed acquaintances". In the subdomain 'Friends', the comments after three days were most often ambivalent and after six and a half weeks they were most often positive. Positive aspects such as "Interest of friends in the child" and "Involvement of friends" were identified. The only negative comments was "Meeting friends" and ambivalent comments such as "Friends are important, you are only able to see that now" or "Friends: others?" were noticed. Aspects coded in 'Others' were most often ambivalent after three days but mostly negative after six and a half weeks. Ambivalent comments such as "Social 
expectations (e.g. from relatives)" or "Less time for social life" and negative ones such as „Being isolated from the outside world“, „Social life on hold”, and "Relationship with friends who do not have children" were identified.

\section{Everyday life}

Aspects coded in everyday life were mentioned more frequently after six and a half weeks compared to three days after birth (Table 2). Comments coded as "Organisation of daily life" were rare and either positive or ambivalent. A positive aspect was "I'm able to manage work and family without any problem". The household was mentioned more often during the seventh week than after three days postpartum and tended to be ambivalent at both stages of assessment. Ambivalent aspects were: "Household a little bit slower" or "Managing the household with two children". Support was very rarely mentioned and only positively: "Support from the social environment". Comments which were coded in 'Others' were never positive after three days but balanced after six and a half weeks. Positive aspects were "To fulfil the requirements of everyday life" as well as "Manage the new routines" and a negative one was "Disorderly process". "New, unknown daily routine ('other-directed')" was an ambivalent quote.

\section{Leisure}

Comments concerning leisure were identified at both time points in a balanced way (Table 2). 'Time for yourself' was mentioned more frequently after six and a half weeks and was sometimes positive but more often negative at both stages of assessment. An example of a positive quote was "I have more private time than before" and a negative one "Less time for myself". Independence was rarely mentioned with similar frequency at both time points. One ambivalent comment indicated “To lose independence”. Quotes about 'Hobbies' were most often negative and not specified at both stages. An ambivalent comment was "Temporarily give up particular hobbies or sports activities". 'Associations, clubs' was rarely mentioned and the comments were negative or ambivalent such as "Less time for associations, clubs". 
Aspects coded in 'Others' were mostly negative after three days but balanced during the seventh week postpartum. Positive comments were "Holiday plans" or "Free time changed, make better use of other priorities" and an ambivalent one was "To have limited free time again".

\section{Work life}

Work life was mentioned more frequently after three days than after six and a half weeks (Table 2). Comments about 'Return to work' occurred more often after three days compared to six and a half weeks. A positive quote was "Work $\rightarrow$ good to know that it will be possible to return $\rightarrow$ without loss!", a negative one "Returning to work would not be possible" and an ambivalent one "Return to work! Work is important but the child even more!". 'Worries about the job' were rare and ambivalent: "Job: will I be able to carry out the same position again, will I receive new tasks". Comments coded into 'Others' were positive such as "I enjoy taking a break from work", negative such as "Significance of the work" or "Professional career" and ambivalent such as "When and where I will be working?".

\section{Financial issues}

Financial aspects were mentioned in equal proportions at both stages of assessment (Table 2), but they were generally rare. No subdomains were identified because the aspects were either unspecific or varied in their meanings. Financial issues were more often negative such as "Finances: maintaining the standard of living? Instalments for the house?", "Financial situation (one wage)" or "Assistance from the government". Positive comments about the financial situation were "Earn money (worth decreases)" and "Financial aspect (parental allowance)".

\section{Further aspects}

A variety of further aspects were classified in four subdomains. Aspects coded into 'Future' were only noticed after three days but not after six and a half weeks. Comments were mostly 
positive such as "Future prospects" but there was also a negative one: "Fear of the future". 'Shift of priority' was indicated more frequently during the first week after birth compared to the seventh week postpartum. The aspects were mostly positive but women did not provide further details. Remarks classified into 'Changed role from being a working woman' were indicated in similar frequencies at both stages of assessment and were mostly ambivalent such as "My role as a housewife" or "Role as being 'only' housewife and mother". Furthermore, a variety of comments were coded as 'Others' at both time points and were most often positive such as "Take everything slowly", "Intensive perception (of the environment, moods, atmosphere, interpersonal relationship, more understanding + more willing to learn, more open)", and "enrichment of own life". Negative aspects were noticed such as "Me as a person with own wishes" and there were also ambivalent aspects such as "Housing situation" and "Burden of responsibility".

\section{Differences between Swiss and German women}

Three days after birth, Swiss mothers tended to indicate more physical aspects being affected by giving birth compared to the German mothers. However, after six and a half weeks the frequencies were similar (Table 3). In contrast, emotional aspects after three days and the general well-being at both stages of assessment were mentioned more frequently in the German than in the Swiss subgroup. In particular, the positive aspects of general wellbeing were identified more frequently by German mothers. Motherhood and family/partnership were the most frequently indicated domains in both subgroups, but after three days, family/partnership, especially the relationship with other children, was mentioned more in the Swiss than in the German subgroup. Social life was identified more in the German subgroup after three days and more frequently in the Swiss subgroup after six and a half weeks. At both stages of assessment, everyday life, leisure and financial issues were identified more frequently by Swiss than German mothers.

\section{Discussion}


This is the first study classifying the responses to the MGI in structured domains and subdomains defining postnatal QoL. Moreover, no previous study has investigated the changes over time and cross-cultural comparison of areas of life affected after childbirth. General aspects of QoL as well as very specific ones for the special life situation after having given birth were identified and differences between both stages of assessment and both countries were recognised.

The domains 'Family and partnership' as well as 'Motherhood' were mentioned most frequently and showed the greatest variety. This indicates that partnership, family adaptations, and the close social network are important aspects of postnatal QoL. Partnership and transition into motherhood and parenthood are related factors because this transition, mostly initiated by the birth of the first child, affects the partnership. ${ }^{26}$ QoLinstruments such as the SF36,${ }^{16}$ widely used in perinatal research but not especially designed for this life situation, have concentrated mainly on physical and mental health. The current study however revealed that family and partnership seem to be more important than physical and mental health for the QoL of women after childbirth. Hill et al., ${ }^{18}$ who designed the Maternal Postpartum Quality of Life Questionnaire, included relational/spouse-partner and relational/family-friends as two of five domains in the tool, which confirms the importance of the aspects family and partnership. Our study also identified details about physical and mental aspects that are specific for the life situation after birth. Happiness and self-esteem were the most specific subdomains in mental well-being and were also identified by Symon et al. ${ }^{19}$. Additionally, our analyses confirmed the findings of other studies using the MGI that tiredness is an important issue of physical well-being while caring for small children. ${ }^{19,21}$ Roeters et al. ${ }^{27}$ found that women with an active lifestyle who combined leisure and long work hours before motherhood had a lower increase of well-being after giving birth compared to women with a less active lifestyle. This might explain why leisure was identified to be a domain of postnatal QoL in our study. The difficult transition for working mothers into motherhood indicates why comments about working life were frequently affected by giving 
birth. Social support, especially from the partner and the family, was found to be associated with postpartum mental health. ${ }^{28}$ Our findings suggest that some women felt isolated after birth and that this was a negative aspect of postnatal QoL. Women with a poor social network might be at risk of lower QoL and further research is needed to establish which kind of interventions could be effective in improving this. We found also additional aspects such as the change of priorities and the changed role from being a working woman. These issues might be accentuated during the postpartum period and be further indications that the life situation after childbirth is a very specific one.

Our study reports on some key differences and similarities in aspects defining postnatal QoL between weeks one and seven postpartum. Changes of QoL over time during the postnatal period were found by different authors and mostly showed improvement. ${ }^{12,14}$ The numerical results of the current studies however found higher MGI scores after three days compared to the seventh week postpartum, however the study concentrated on the very first days and weeks after birth. ${ }^{11}$ The details of the areas of life affected by giving birth suggest explanations for the decline of QoL during the first postnatal weeks: women indicated more fatigue, a worsening relationship with the partner, negatively affected social life and leisure as well as ambivalence about everyday life after six and a half weeks compared to three days after birth. Couples, especially those with pre-existing problems prior to birth or with a demanding infant showed postnatal deterioration in their partnership. ${ }^{26}$ Our results indicate that the decline in relationships of parents could start quickly after birth. Symon et al. ${ }^{19}$ found that women who commented on having a worse relationship with their partner or other family members had MGI scores in the lowest quartile. Associations between comments and MGI scores was not researched in our study as the focus was on creating a clear system of domains and subdomains defining postnatal quality of life, and further research is needed to fully understand these associations.

The numerical results of our study did not find significant differences in MGI scores between German and Swiss mothers. ${ }^{11}$ In contrast, the content analysis of the areas of life affected by 
the motherhood revealed important differences between the study groups. The increased identification of physical aspects in Swiss mothers, especially the negative ones, could be explained by the higher caesarean section rates in the Swiss study site. ${ }^{11}$ Furthermore, Swiss mothers more frequently mentioned the relationship with other children, which might be explained by the higher rate of multiparae. ${ }^{11}$ Financial aspects, mostly negatively affected, were also more frequent in Swiss mothers but in Switzerland the Gross Domestic Product per head is higher than in Germany ${ }^{29}$ and it seems that financial worries increase within an environment with more money. The reasons for this finding remain unclear. Further differences, such as the higher frequencies of comments related to the everyday life and leisure in the Swiss populations might also be due to the higher frequency in multiparae in the Swiss subgroup; however, no previous studies have investigated cross-cultural comparison of such details of postnatal QoL. It also remains unclear how differences in the length of maternity or paternity leave (14 months in Germany in total for both parents and 14 weeks in Switzerland for mothers only) ${ }^{30-32}$ are associated with postnatal QoL and the identified cross-cultural differences. Further research is needed to fully understand the reasons for the cultural differences identified in our study.

Symon et al. ${ }^{19}$ developed the MGI to assess postnatal quality of life during postnatal checkups. The scores of the instrument enable the detection of women with low QoL who might need additional support. The comments mothers make when completing the MGI provide additional information and give indications about which aspects were most affected by life with a baby. The findings of the current study indicate specific areas of life which are affected by the motherhood. For example, women reported lack of time after childbirth suggesting that postpartum women need sufficient support to find time for themselves, their family and to sleep. Healthcare providers are invited to listen to mothers in order to provide individualised care and support. Considering a salutogenic approach and fostering health promotion, maternity care should aim to improve QoL of mothers and their families. ${ }^{6}$ 
A strength of this study was that data of a thoroughly conducted two-stage survey with good participation rates was used for analysis. The follow-up at a median of six and a half weeks postpartum was conducted with a subsample of the same women, and therefore the differences between the two phases of assessment were not due to interpersonal variations. A further strength was that the method used was clearly described and led to a wellstructured system of domains and subdomains. Additionally, data collection was conducted in two hospitals which were located in two countries. However, despite this international character, the study area was restricted and results might not be valid for other geographical locations. Furthermore, some cultural differences in comments might be due to differences in parity, maternity care and maternity leave; however, in this qualitative study we were not able to assess the exact impact of these factors. An additional limitation of the study was that examples of areas of life were provided on the MGI form and used by many women. The main domain 'General well-being' was a consequence of the example "How they feel", because it was used frequently and did not clearly indicate if this feeling was physical or emotional. Additionally, many women used key words and key terms because of the limited space on one row and therefore, a larger part of the study material was not rich in content. Furthermore, it was not always clear if the information about positive, negative and ambivalent areas of life was generally valid information or only valid for the present situation.Self-completion of the questionnaires instead of conducting interviews, both methods being used in previous studies, prevented the possibility to dig deeper and gain additional information. ${ }^{19,20}$ Nevertheless, some women were imaginative and creative and provided an interesting insight into aspects of their QoL. However, the consequently wide range of domains and subdomains, which was also noticed by Symon et al. ${ }^{17}$ as well as the relatively small sample size of our study, led to some subdomains which were only mentioned rarely. The current study focused on the classification of the comments into a detailed system of domains and subdomains as well as on the differences between both stages of assessment and both countries, but did not investigate the associations between domains and subdomains with MGI scores as other studies researching the MGI comments 
had done. ${ }^{19,20}$ This could be considered as a further weakness of the study. However, focused research on the comments enabled detailed assessment. Further research will be needed to investigate the associations of such a detailed system of domains and subdomains with the MGI scores and additional aspects. Furthermore, based on the findings of this study, it appears worthwhile to set up a more in-depth qualitative study allowing for a deeper understanding of the women's situation on an individual level, their understanding of quality of life and its possible determinants.

\section{Conclusion}

Women after childbirth mentioned a wide variety of areas of life affected by having a baby. Mothers during the postnatal period faced challenges to find their new role inside and outside their families and lacked time for themselves, their leisure, their partner and their other children. However, they also welcomed the slowdown in the rhythm of life and experienced overwhelming maternal feelings. This study identified domains and subdomains defining postnatal QoL which differed between weeks one and six and a half postpartum as well as between German and Swiss mothers, suggesting that postnatal QoL is a concept that changes over time and shows cross-cultural differences for new mothers. Using the MGI as a diagnostic tool may assist midwives and other maternity care providers to help identify the specific care needs of individual women.

\section{Acknowledgements}

We like to thank Dr. Andrew Symon for permission to use the MGI, the hospitals in Switzerland and Germany for facilitating this study and, above all, the women who made this study possible by completing our research instruments. 


\section{References}

1. Anderson KL, Burckhardt CS. Conceptualization and measurement of quality of life as an outcome variable for health care intervention and research. J Adv Nurs 1999; 29(2): 298-306.

2. Ventegodt S, Merrick J, Andersen NJ. Quality of life theory I. The IQOL theory: an integrative theory of the global quality of life concept. ScientificWorldJournal 2003; 3: 103040 .

3. World HEalth Organisation (WHO). Measuring Quality of Life, the World Health Organization quality of life instruments (the WHOQOL-100 and the WHOQOL-BREF). 1997; Available at: http://www.who.int/mental_health/media/68.pdf. Accessed 14.11.2017, 2017.

4. Farquhar M. Definitions of quality of life: a taxonomy. J Adv Nurs 1995; 22(3): 502-8.

5. Mogos MF, August EM, Salinas-Miranda AA, Sultan DH, Salihu HM. A Systematic Review of Quality of Life Measures in Pregnant and Postpartum Mothers. Appl Res Qual Life 2013; 8(2): 219-50.

6. Smith V, Daly D, Lundgren I, Eri T, Benstoem C, Devane D. Salutogenically focused outcomes in systematic reviews of intrapartum interventions: a systematic review of systematic reviews. Midwifery 2014; 30(4): e151-6.

7. Tungchama F, Piwuna C, Armiya'u A, et al. Independent socio-demographic and clinical correlates associated with the perception of quality of life of women with postpartum depressionin North-central, Nigeria. Int J Psychiatry Clin Pract 2017; : 1-10.

8. Mousavi SA, Mortazavi F, Chaman R, Khosravi A. Quality of life after cesarean and vaginal delivery. Oman Med J 2013; 28(4): 245-51.

9. Shaw E, Levitt C, Wong S, Kaczorowski J, McMaster University Postpartum Research Group. Systematic review of the literature on postpartum care: effectiveness of postpartum support to improve maternal parenting, mental health, quality of life, and physical health. Birth 2006; 33(3): 210-20.

10. Baghirzada L, Downey KN, Macarthur AJ. Assessment of quality of life indicators in the postpartum period. Int J Obstet Anesth 2013; 22(3): 209-16.

11. Grylka-Baeschlin S, van Teijlingen E, Gross MM. Cultural differences in postnatal quality of life among German-speaking women - a prospective survey in two countries. BMC Pregnancy Childbirth 2014; 14: 277,2393-14-277.

12. Emmanuel EN, Sun J. Health related quality of life across the perinatal period among Australian women. J Clin Nurs 2014; 23(11-12): 1611-9.

13. Symon AG, Dobb BR. An exploratory study to assess the acceptability of an antenatal quality-of-life instrument (the Mother-generated Index). Midwifery 2008; 24(4): 442-50. 
14. Bahrami N, Karimian Z, Bahrami S, Bolbolhaghighi N. Comparing the postpartum quality of life between six to eight weeks and twelve to fourteen weeks after delivery in iran. Iran Red Crescent Med J 2014; 16(7): e16985.

15. Gebuza G, Kazmierczak M, Mieczkowska E, Gierszewska M, Kotzbach R. Life satisfaction and social support received by women in the perinatal period. Adv Clin Exp Med 2014; 23(4): 611-9.

16. Ware JE,Jr, Sherbourne CD. The MOS 36-item short-form health survey (SF-36). I. Conceptual framework and item selection. Med Care 1992; 30(6): 473-83.

17. Symon A, McGreavey J, Picken C. Postnatal quality of life assessment: validation of the Mother-Generated Index. BJOG 2003; 110(9): 865-8.

18. Hill PD, Aldag JC, Hekel B, Riner G, Bloomfield P. Maternal Postpartum Quality of Life Questionnaire. J Nurs Meas 2006; 14(3): 205-20.

19. Symon A, MacDonald A, Ruta D. Postnatal quality of life assessment: introducing the mother-generated index. Birth 2002; 29(1): 40-6.

20. Symon A, Downe S, Finlayson KW, Knapp R, Diggle P, SHIP trial team. The feasibility and acceptability of using the Mother-Generated Index (MGI) as a Patient Reported Outcome Measure in a randomised controlled trial of maternity care. BMC Med Res Methodol 2015; 15: 100,015-0092-0.

21. Nagpal J, Dhar RS, Sinha S, Bhargava V, Sachdeva A, Bhartia A. An exploratory study to evaluate the utility of an adapted Mother Generated Index (MGI) in assessment of postpartum quality of life in India. Health Qual Life Outcomes 2008; 6: 107,7525-6-107.

22. Khabiri R, Rashidian A, Montazeri A, Symon A, Foroushani AR, Arab M, Rashidi BH. Validation of the Mother-Generated Index in Iran: A Specific Postnatal Quality-of-Life Instrument. Int J Prev Med 2013; 4(12): 1371-9.

23. Grylka-Baeschlin S, van Teijlingen E, Stoll K, Gross MM. Translation and validation of the German version of the Mother-Generated Index and its application during the postnatal period. Midwifery 2015; 31(1): 47-53.

24. Forrest Keenan $\mathrm{K}$, van Teijlingen $\mathrm{E}$. The quality of qualitative research in family planning and reproductive health care. J Fam Plann Reprod Health Care 2004; 30(4): 257-9.

25. Mayring P. Qualitative Inhaltsanalyse, Grundlagen und Techniken, 12. aktualisierte und überarbeitet Ausgabe. 12.th ed. Weinheim und Basel: Beltz-Verlag; 2015.

26. Doss BD, Rhoades GK. The transition to parenthood: impact on couples' romantic relationships. Curr Opin Psychol 2017; 13: 25-8. 
27. Roeters A, Mandemakers JJ, Voorpostel M. Parenthood and Well-Being: The Moderating Role of Leisure and Paid Work. Eur J Popul 2016; 32(3): 381-401.

28. Reid KM, Taylor MG. Social support, stress, and maternal postpartum depression: A comparison of supportive relationships. Soc Sci Res 2015; 54: 246-62.

29. Eurostat. National accounts and GDP. 2017; Available at:

http://ec.europa.eu/eurostat/statistics-explained/index.php/National_accounts_and_GDP. Accessed 16.11.2017, 2017.

30. Schweizerische Eidgenossenschaft. Bundesgesetz betreffend die Ergänzung des Schweizerischen Zivilgesetzbuches (Fünfter Teil: Obligationenrecht). Stand 1. April2017, 2011; Available at: https://www.admin.ch/opc/de/classified-compilation/19110009/index.html. Accessed 26.12.2017.

31. Bundesministerium für Familien, Senioren, Frauen und Jugend. Elterngeld und Elternzeit, Das Bundeselterngeld und Elternzeitgesetz. 2017; Available at:

https://www.bmfsfj.de/bmfsfj/service/publikationen/elterngeld--elterngeldplus-und-elternzeit/73770?view=DEFAULT. Accessed 26.12.2017.

32. Eidgenössisches Volkswirtschaftsdepartament EVD, Staatsekretariat für Wirtschaft SECO. Mutterschaft, Schutz der Arbeitnehmerinnen. 2016; Available at: https://www.seco.admin.ch/seco/de/home/Publikationen_Dienstleistungen/Publikationen_und _Formulare/Arbeit/Arbeitsbedingungen/Broschuren/mutterschaft-_-schutz-derarbeitnehmerinnen.html. Accessed 26.12.2017. 


\section{Tables}

Table 1: Levels of agreement of two researches for coding the areas of life

\begin{tabular}{lcccc}
\hline Time after birth & $\begin{array}{c}\text { Areas of life } \\
\text { listed, } \mathbf{n}\end{array}$ & $\begin{array}{c}\text { Full agreement, } \\
\mathbf{n}(\%)^{\mathbf{1}}\end{array}$ & $\begin{array}{c}\text { Partial agreement, } \\
\mathbf{n}(\%)^{\mathbf{2}}\end{array}$ & $\begin{array}{c}\text { Disagreement, } \\
\mathbf{n}(\%)^{\mathbf{3}}\end{array}$ \\
\hline 3 days & 697 & $499(71.6)$ & $102(14.6)$ & $96(13.8)$ \\
\hline 6.5 weeks & 504 & $373(74.0)$ & $68(13.5)$ & $63(12.5)$ \\
\hline Total & 1,201 & $872(72.6)$ & $170(14.2)$ & $159(13.2)$ \\
\hline
\end{tabular}

${ }^{1}$ Full agreement: agreement for the main domain and the subdomain

2 Partial agreement: agreement only for the main domain

${ }^{3}$ Disagreement: no agreement of the main domain and the subdomain 
Table 2: Absolute and relative frequencies of comments in the main domains and subdomains at both stages of assessment

\begin{tabular}{|c|c|c|}
\hline Main domain / Subdomain & $\begin{array}{l}3 \text { days pp* } \\
124 \text { women; } \\
\text { n=691 aspects; } \\
n(\%)\end{array}$ & $\begin{array}{l}6.5 \text { weeks pp* } \\
82 \text { women; } \\
n=504 \text { aspects; } \\
n(\%)\end{array}$ \\
\hline Physical well-being & $60(8.7)$ & $53(10.5)$ \\
\hline Not specified ${ }^{1}$ & 0 & $2(0.4)$ \\
\hline Physical condition & $31(4.5)$ & $21(4.2)$ \\
\hline Pain & $3(0.4)$ & 0 \\
\hline Tiredness, sleep & $2(0.3)$ & $8(1.6)$ \\
\hline Body awareness & $5(0.7)$ & $6(1.2)$ \\
\hline Sport & $3(0.4)$ & $2(0.4)$ \\
\hline Others $^{2}$ & $16(2.3)$ & $14(2.8)$ \\
\hline Mental well-being & $48(6.9)$ & $33(6.5)$ \\
\hline Not specified ${ }^{1}$ & $3(0.4)$ & 0 \\
\hline Emotional aspects & $27(3.9)$ & $17(3.4)$ \\
\hline Happiness & $3(0.4)$ & $1(0.2)$ \\
\hline Self-esteem & $3(0.4)$ & $3(0.6)$ \\
\hline Others $^{2}$ & $12(1.7)$ & $12(2.4)$ \\
\hline General well-being & $47(6.8)$ & $37(7.3)$ \\
\hline How I feel & $41(5.9)$ & $31(6.2)$ \\
\hline Others $^{2}$ & $6(0.9)$ & $6(1.2)$ \\
\hline Motherhood & $129(18.7)$ & $78(15.5)$ \\
\hline Feelings for the baby & $76(11.0)$ & $54(10.7)$ \\
\hline Mother-child relationship & $14(2.0)$ & $6(1.2)$ \\
\hline Worries about the baby & $3(0.4)$ & $2(0.4)$ \\
\hline Breastfeeding & $6(0.9)$ & $3(0.6)$ \\
\hline Pregnancy and birth experience & $11(1.6)$ & 0 \\
\hline Maternity care in hospital (birth / postpartum) & $4(0.6)$ & 0 \\
\hline Others $^{2}$ & $15(2.2)$ & $13(2.6)$ \\
\hline Family and partnership & $188(27.2)$ & $145(28.8)$ \\
\hline Not specified ${ }^{1}$ & $2(0.3)$ & $5(1.0)$ \\
\hline Relationship with partner & $96(13.9)$ & $62(12.3)$ \\
\hline Sexuality & $3(0.4)$ & $2(0.4)$ \\
\hline Relationship with other children & $27(3.9)$ & $15(3.0)$ \\
\hline Relationship with other family members & $28(4.1)$ & $23(4.6)$ \\
\hline Time for partner and family & $5(0.7)$ & $6(1.2)$ \\
\hline Others $^{2}$ & $27(3.9)$ & $32(6.3)$ \\
\hline
\end{tabular}




\begin{tabular}{|c|c|c|}
\hline Social life & $54(7.8)$ & $58(11.5)$ \\
\hline Not specified ${ }^{1}$ & $22(3.2)$ & $25(5.0)$ \\
\hline Social contacts & $7(1.0)$ & $4(0.8)$ \\
\hline Friends & $15(2.2)$ & $21(4.2)$ \\
\hline Others $^{2}$ & $10(1.4)$ & $8(1.6)$ \\
\hline Everyday life & $15(2.2)$ & $26(5.2)$ \\
\hline Not specified ${ }^{1}$ & $2(0.3)$ & $3(0.6)$ \\
\hline Organisation of daily life & $2(0.3)$ & $1(0.2)$ \\
\hline Household & $5(0.7)$ & $11(2.2)$ \\
\hline Support & $1(0.1)$ & $1(0.2)$ \\
\hline Others $^{2}$ & $5(0.7)$ & $10(2.0)$ \\
\hline Leisure & $34(4.9)$ & $21(4.2)$ \\
\hline Not specified ${ }^{1}$ & $7(1.0)$ & $3(0.6)$ \\
\hline Time for themselves & $3(0.4)$ & $5(1.0)$ \\
\hline Independence & $3(0.4)$ & $2(0.4)$ \\
\hline Hobbies & $8(1.2)$ & $5(1.0)$ \\
\hline Associations, clubs & $3(0.4)$ & $2(0.4)$ \\
\hline Others $^{2}$ & $10(1.4)$ & $4(0.8)$ \\
\hline Work life & $67(9.7)$ & $25(5.0)$ \\
\hline Not specified ${ }^{1}$ & $22(3.2)$ & $5(1.0)$ \\
\hline Return to work & $31(4.5)$ & $12(2.4)$ \\
\hline Worries about the job & $1(0.1)$ & $1(0.2)$ \\
\hline Others $^{2}$ & $13(1.9)$ & $7(1.4)$ \\
\hline Financial issues & $8(1.2)$ & $6(1.2)$ \\
\hline Further aspects & $41(5.9)$ & $22(4.4)$ \\
\hline Future & $9(1.3)$ & 0 \\
\hline Shift of priorities & $5(0.7)$ & $1(0.2)$ \\
\hline Changed role from being a working woman & $5(0.7)$ & $3(0.6)$ \\
\hline Others $^{2}$ & $32(4.6)$ & $18(3.6)$ \\
\hline
\end{tabular}

${ }^{*} \mathrm{pp}=$ postpartum; ${ }^{1}$ Not specified=main domain was mentioned by the woman without providing any details; ${ }^{2}$ Others $=$ details were provided by the woman but the comment could not be classified in any listed subdomain 
Table 3: Average number of comments per women in the German and Swiss subgroups, three days and six and a half weeks after birth

\begin{tabular}{lcccc}
\hline Domain & \multicolumn{2}{c}{ 3 days } & \multicolumn{2}{c}{ 6.5 weeks } \\
\hline & $\begin{array}{c}\text { Average } \\
\text { number of } \\
\text { comments/ } \\
\text { women }\end{array}$ & $\begin{array}{c}\text { Switzerland, } \\
\mathbf{n = 5 0} \\
\text { Average } \\
\text { number of } \\
\text { comments/ } \\
\text { women }\end{array}$ & $\begin{array}{c}\text { Germany, } \mathbf{n = 4 4} \\
\text { Average } \\
\text { number of } \\
\text { women }\end{array}$ & $\begin{array}{c}\text { Switzerland, } \\
\mathbf{n = 3 8} \\
\text { Average } \\
\text { number of } \\
\text { comments/ } \\
\text { women }\end{array}$ \\
\hline Physical well-being & 0.38 & $\mathbf{0 . 6 4}$ & 0.68 & 0.61 \\
\hline Mental well-being & 0.43 & 0.32 & 0.41 & 0.39 \\
\hline General well-being & $\mathbf{0 . 4 5}$ & 0.28 & $\mathbf{0 . 5 2}$ & 0.37 \\
\hline Motherhood & 0.97 & 1.14 & 0.93 & 0.97 \\
\hline Family and partnership & 1.39 & $\mathbf{1 . 7 0}$ & 1.80 & 1.74 \\
\hline Social life & 0.47 & 0.38 & 0.66 & 0.76 \\
\hline Everyday life & 0.08 & $\mathbf{0 . 1 8}$ & 0.23 & $\mathbf{0 . 4 2}$ \\
\hline Leisure & 0.19 & $\mathbf{0 . 4 0}$ & 0.14 & $\mathbf{0 . 3 9}$ \\
\hline Work life & 0.55 & 0.52 & 0.27 & 0.34 \\
\hline Financial issues & 0.03 & $\mathbf{0 . 1 2}$ & 0.05 & $\mathbf{0 . 1 1}$ \\
\hline Further aspects & 0.46 & 0.32 & 0.16 & 0.39 \\
\hline
\end{tabular}




\section{Figures}

Figure 1: MGI questionnaire (the areas in Step 1 were listed by the women themselves)

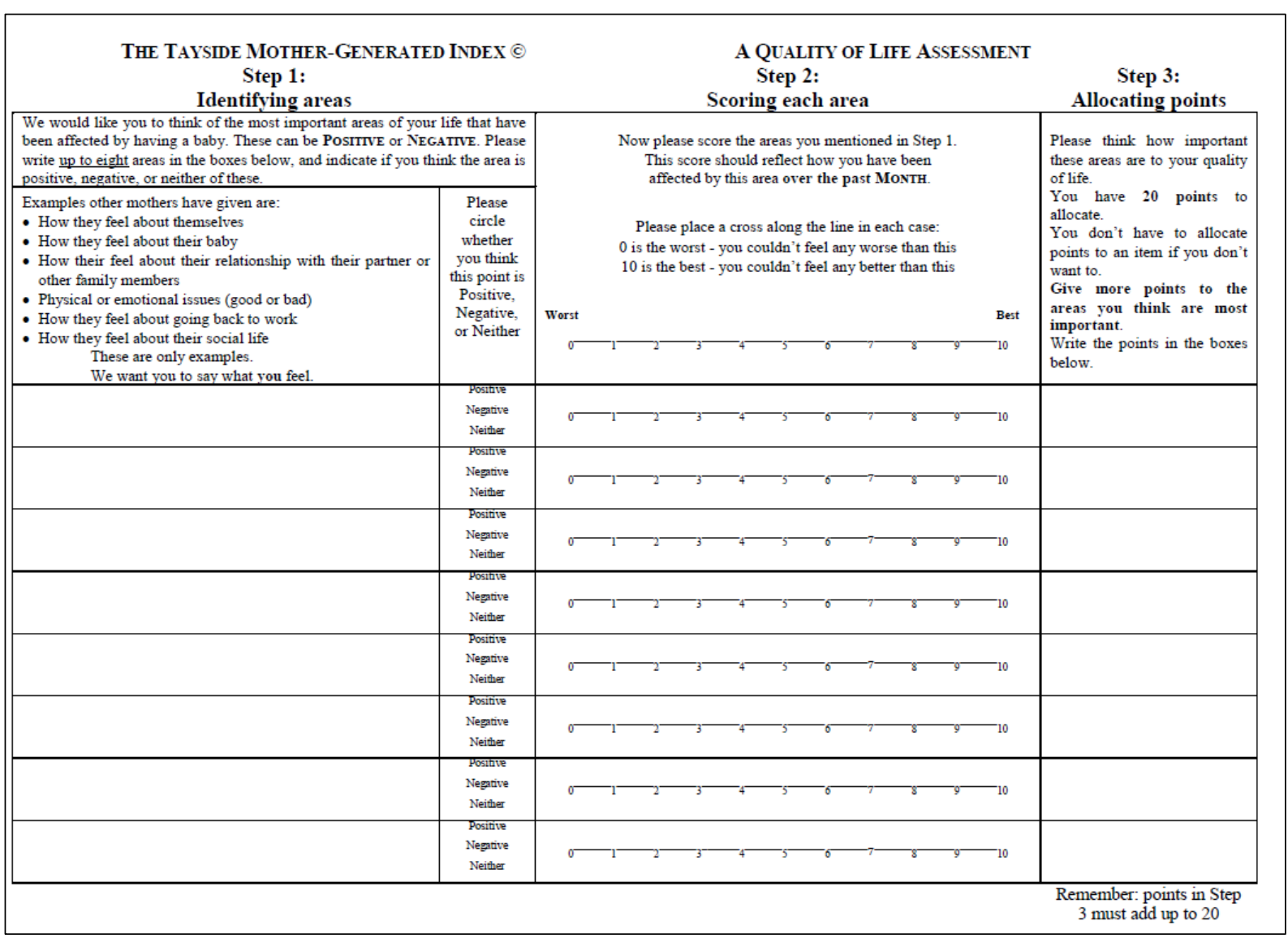

